\title{
Implementasi Pendidikan Inklusi pada Jenjang PAUD
}

\author{
Insiatun Insiatun, Gardiana Karya, Ediyanto Ediyanto*, Asep Sunandar \\ Universitas Negeri Malang, Jl. Semarang No. 5 Malang, Jawa Timur, Indonesia \\ *Penulis korespondensi, Surel: ediyanto.fip@um.ac.id
}

Paper received: 2-11-2021; revised: 17-11-2021; accepted: 23-11-2021

\begin{abstract}
Inclusive education in early childhood begins by accommodating children's needs, identifying children with special needs, as well as mapping the potential developments and obstacles of children today and in the future. This study aims to analyze the extent to which the implementation of inclusive education in early childhood education institutions in one of the early childhood education institutions in the city of Bandung. First, researchers collect information about the implementation of inclusive education in early childhood education institutions, the obstacles and constraints experienced, program optimization, and follow-up to the problems encountered by PAUD in providing inclusive education. Then, researchers perform data analysis by enriching information, looking for relationships, comparing, finding patterns based on the original data.
\end{abstract}

Keywords: inclusive education; early childhood; student with special needs

\begin{abstract}
Abstrak
Pendidikan inklusi pada anak usia dini dimulai dengan mengakomodasi kebutuhan anak, mengidentifikasi kebutuhan khusus anak, serta memetakan potensi perkembangan dan hambatan anak saat ini maupun di masa depan. Penelitian ini bertujuan untuk menganalisis sejauh mana implementasi pendidikan inklusi pada lembaga pendidikan anak usia dini di salah satu lembaga pendidikan anak usia dini di Kota Bandung. Peneliti menghimpun informasi mengenai implementasi pendidikan inklusi di lembaga pendidikan anak usia dini, hambatan dan kendala yang dialami, optimalisasi program, serta tindak lanjut dari permasalahan-permasalahan yang dialami PAUD dalam mengadakan pendidikan inklusif. Peneliti melakukan analisis data dengan memperkaya informasi, mencari hubungan, membandingkan, menemukan pola atas dasar data aslinya.
\end{abstract}

Kata kunci: pendidikan inklusi; anak usia dini; siswa berkebutuhan khusus

\section{Pendahuluan}

Pendidikan merupakan hak asasi setiap warga negara Indonesia dan untuk itu setiap warga negara termasuk anak berkebutuhan khusus berhak memperoleh pendidikan yang bermutu sesuai dengan kebutuhan, minat dan bakat yang dimilikinya tanpa memandang status sosial, ras, etnis, agama dan gender. Pemerataan dan peningkatan mutu pendidikan akan membuat warga negara Indonesia memiliki kecakapan hidup (life skills) sehingga mendorong tegaknya pembangunan manusia seutuhnya yang dijiwai nilai-nilai Pancasila (Insiatun, 2016).

Sebagaimana anak normal lainnya, anak berkebutuhan khusus juga berhak mendapatkan pendidikan. Hal tersebut sejalan dengan prinsip Education for All (pendidikan untuk semua) yang merupakan penjabaran UUD 1945 mengenai pendidikan untuk warga negara Indonesia. Sebuah kewajiban dan tanggung jawab pemerintah sebagai penyelenggara negara dalam kehidupan negeri ini. Maka, pemerataan kesempatan mengikuti proses pendidikan dan pembelajaran tidak hanya terbatas pada kelompoknya yang mampu, namun harus menyeluruh untuk setiap lapisan masyarakat (Purwani, 2014; Priyanti et al, 2016). 
Sekolah inklusi merupakan salah satu bentuk pemerataan dan bentuk perwujudan pendidikan tanpa diskriminasi dimana anak berkebutuhan khusus dan anak-anak pada umumnya dapat memperoleh pendidikan yang sama. Pendidikan inklusi merupakan bentuk pelayanan pendidikan khusus yang mensyaratkan agar semua anak berkebutuhan khusus dapat menerima pendidikan yang setara dikelas biasa bersama teman-teman usianya. Selama ini anak - anak yang memiliki perbedaan kemampuan (difabel) disediakan fasilitas pendidikan khusus disesuaikan dengan derajat dan jenis difabelnya yang disebut dengan Sekolah Luar Biasa (SLB). Secara tidak disadari sistem pendidikan SLB telah membangun tembok eksklusifisme bagi anak - anak yang berkebutuhan khusus. Penyelenggaraan sekolah inklusi bagi anak berkebutuhan khusus hendaknya menciptakan lingkungan yang menyenangkan, ramah dan dapat menumbuhkan rasa percaya diri siswa berkebutuhan khusus untuk mengenyam pendidikan yang layak sesuai dengan hak mereka. Kenyataan penyelenggara sekolah inklusi di Indonesia masih belum sesuai dengan konsep yang dikemukakan dan pedoman penyelenggaraan, baik dari segi siswa, kualifikasi guru, sarana dan prasarana, dukungan orang tua dan masyarakat. Penyelenggaraan sekolah inklusi di Indonesia saat ini masih menjadi fenomena (Darma \& Rusyidi, 2015).

Pemerintah memberikan kesempatan yang sama dalam pendidikan. Melalui Pusat Pembinaan dan Pemberdayaan Guru dan Tenaga Kependidikan Taman Kanak-kanak dan Pendidikan Luar Biasa (PPPPTK TK \& PLB), pemerintah memberikan pelatihan dan layanan kepada para guru di bidang pendidikan inklusif dan pendidikan luar biasa. Pelatih guru di PPPPTK TK \& PLB disebut Widyalswara (Ediyanto et al., 2017). Penyediaan sekolah inklusif di Indonesia menuntut pemenuhan beberapa aspek Pendidikan Inklusif. Pemenuhan kebutuhan tersebut meliputi kurikulum, sarana dan prasarana, guru, dan pembelajaran yang sesuai dengan prinsip Pendidikan Inklusif. Guru di kelas inklusif harus memiliki kompetensi untuk mengajar siswa berkebutuhan khusus. Selain itu, kelas inklusif juga membutuhkan Guru Bimbingan Khusus sebagai desain instruksional atau sebagai team teaching. Untuk tingkat Taman Kanak-kanak jumlah guru sebanyak 85.499 guru. Standar Kompetensi Guru Pembina mengacu pada Peraturan Menteri Pendidikan Nasional Nomor 16 Tahun 2007 - Standar Kualifikasi Akademik dan Kompetensi Guru dan Menteri Pendidikan Nasional Nomor 32 Tahun 2008 - Standar Kualifikasi Akademik dan Kompetensi Guru Pendidikan Luar Biasa. Secara umum ada empat kompetensi yang harus dikuasai oleh Guru Pembimbing Khusus, yaitu Kepribadian, Sosial, Pedagogik, dan Standar Profesi (Ediyanto et al., 2018).

Dalam implementasi PAUD inklusif sebuah lembaga tidak bisa berjalan sendiri untuk mencapai tujuannya. Ada berbagai faktor yang mempengaruhi keberhasilan dalam mencapai tujuan tersebut. Baik itu sarana dan prasarana maupun sumber daya manusia di dalamnya. Namun terlepas dari kedua faktor tersebut, jika dikaitkan dengan Tri Pusat Pendidikan maka ada 3 lingkungan yang akan mempengaruhi pendidikan pada anak yakni keluarga, sekolah dan masyarakat. Adapun tujuan PAUD inklusif yaitu: 1. Memberikan kesempatan yang seluas luasnya kepada anak yang memiliki kelainan fisik, emosional, mental dan sosial atau memiliki potensi kecerdasan dan/atau bakat istimewa untuk memperoleh pendidikan yang sesuai dengan kebutuhan dan kemampuannya. 2. Mewujudkan penyelenggaraan pendidikan yang menghargai keanekaragaman tidak diskriminatif bagi semua anak sudah seharusnya anak inklusif mendapatkan haknya yaitu memperoleh pendidikan di sekolah inklusif. Terbatasnya PAUD inklusif menyebabkan anak inklusif usia dini mengalami kesulitan mengakses pendidikan yang seharusnya menjadi haknya. Jika anak inklusi dapat belajar maka anak akan merasa tenang, percaya diri, merasa dihargai, dilindungi, disayangi, bahagia dan bertanggung 
jawab. Inklusi terjadi pada semua lingkungan sosial anak, pada keluarga, kelompok teman sebaya, sekolah, dan institusi kemasyarakatan lainnya, tanpa melupakan prinsip humanisme, liberalisme, pluralisme, demokratis, menghormati hak asasi manusia (Windarsih et al., 2017).

\section{Metode}

Metode penelitian yang diterapkan adalah dengan melakukan tinjauan literatur dan observasi. Tinjauan literatur dilakukan dengan memilah dan memilih artikel dari jurnal perreview yang diterbitakan pada tahun 2010 sampai dengan tahun 2021. Langkah-langkah yang diterapkan pada penelitian ini adalah dengan memilih kata kunci sesuai pertanyaan pada penelitian ini terkait pendidikan inklusi pada jenjang paud. Observasi dilaksanakan dengan mewawancari salah satu tenaga pendidik yang berkerja di sekolah tersebut..

\section{Hasil dan Pembahasan}

Sekolah PAUD Internasional ini sudah melaksanakan prinsip menyeluruh yang memandu semua kebijakan, rencana, dan praktik. Kurikulum nasional hingga internasional dan sistem penilaian terkait dirancang untuk merespons efektif untuk semua pelajar baik anak berkebutuhan khusus maupun non berkebutuhan khusus. Semua mitra yang bekerja dengan siswa usia dini berkebutuhan khusus dan keluarganya memahami dan mendukung tujuan kebijakan untuk mengimplementasikan pendidikan inklusi dan kesetaraan dalam pendidikan.

Adanya sistem pemantauan kehadiran, partisipasi, dan pencapaian semua peserta didik dalam sistem pendidikan inklusi sudah dilaksanakan dengan baik. Staf senior di sekolah memberikan kepemimpinan dalam inklusi dan keadilan dalam implementasi pendidikan Para pemimpin di semua tingkatan mengartikulasikan tujuan kebijakan yang konsisten untuk mengembangkan pendidikan inklusi dan kesetaraan praktik pendidikan di sekolah PAUD tersebut. Para pemimpin di semua tingkatan menentang pendidikan yang tidak inklusif, diskriminatif dan tidak adil pada implementasi di sekolah tersebut. Ada dukungan khusus untuk siswa berkebutuhan khusus di sekolah tersebut seperti pemberian shadow teacher dan pemberian jam khusus untuk anak abk.

Semua layanan dan lembaga yang terlibat di sekolah PAUD tersebut sudah bekerjasama dengan sekolah internasional di negara lain dan dengan peserta didik dan keluarganya bekerja sama mengkoordinasikan kebijakan dan praktik pendidikan yang inklusif dan adil. Sumber daya, baik manusia maupun keuangan, didistribusikan dengan cara yang berpotensi menguntungkan siswa berkebutuhan khusus. Ada peran yang jelas, dalam mempromosikan inklusi dan kesetaraan dalam pendidikan melalui media sosial atau kegiatan tertentu.

Sekolah dan pusat pembelajaran lainnya juga melakukan strategi untuk mendorong kehadiran, partisipasi, dan prestasi semua peserta didik dari komunitas siswa berkebutuhan khusus. Guru dan staf pendukung di sekolah tersebut sudah dipersiapkan untuk menanggapi keragaman pelajar. Guru dan staf pendukung memiliki kesempatan untuk mengambil bagian dalam profesional berkelanjutan pengembangan terkait praktik yang inklusif dan adil di sekolah tersebut.

Adapun prinsip-prinsip yang telah dilaksanakan di sekolah PAUD tersebut adalah penyelenggara pendidikan inklusif adalah menggunakan prinsip manajemen berbasis sekolah yang meliputi perencanaan dan evaluasi program sekolah yaitu melakukan perencanaan sesuai dengan kebutuhannya untuk meningkatkan mutu sekolah berbasis inklusi. Sekolah telah mewujudkan prinsip inklusifitas sejak dari perencanaan, proses penyelenggaraan, 
pemantauan atau pengawasan hingga penyusunan rencana tindak lanjut penyelenggara program sekolah. Dalam pengajaran dengan pendekatan individu menggunakan tiga langkah kegiatan utama yaitu, asesmen (assessment), intervensi (intervention), dan evaluasi (evaluation). Asesmen adalah suatu penilaian yang komprehensif dan melibatkan anggota tim untuk mengetahui kelemahan dan kekuatan anak. Intervensi ada yang dikerjakan untuk membangun tingkah laku yang dikehendaki, adapun untuk meniadakan tingkah laku yang tidak dikehendaki. Membangun tingkah laku yang dikehendaki dilakukan dengan cara menceritakan tingkah laku tersebut dan menganjurkan agar siswa melakukannya. proses pembelajaran dikatakan berhasil apabila terjadi perubahan perilaku yang positif pada diri peserta didik seluruhnya atau setidak tidaknya sebagian besar. Dalam pembelajaran yang dilakukan sudah mengikuti aturan, baik dari persiapan, kurikulum dan implementasinya sudah diterapkan walaupun masih terdapat kesulitan bagi guru untuk menyeimbangkan pembelajaran untuk PAUD inklusif, karena sangatlah mempunyai berbagai macam kendala agar anak inklusi mau diajak bekerjasama dan mengikuti pembelajaran sebagaimana layaknya anak normal. Semua fasilitas di sekolah yang sangat baik. Alat permainan edukatif nya pun sudah dapat dikatakan lebih dari cukup. Setiap anak sudah dibantu helper/ shadow teacher satu orang, dan helper/ shadow teacher tersebut ikut masuk di ruang kelas karena akan sangat membantu guru jika anak inklusif tersebut tiba-tiba membutuhkan tenaganya.

Ada juga kecenderungan orang tua yang memiliki anak inklusif tidak mau berterus terang keseluruhan pada sekolahnya hal ini sangat menyulitkan lembaga yang menyelenggarakan PAUD inklusi serta masih mahalnya biaya anak inklusif sehingga masih dapat dihitung oleh jari anak inklusi yang sekolah bersama-sama anak normal. Perlunya dukungan yang sangat besar baik dari pemerintah pusat maupun pemerintah daerah demi terjadinya terbentuknya pendidikan inklusif yang baik.

Tabel 1. Dimensi utama implementasi sistem pendidikan yang inklusif

\begin{tabular}{ll}
\hline Dimensi & \multicolumn{1}{c}{ Deskripsi } \\
\hline Konsep & - Inklusi dan kesetaraan adalah prinsip menyeluruh yang memandu semua kebijakan, \\
& rencana, dan praktik. \\
& - Kurikulum nasional dan sistem penilaian terkait dirancang untuk merespons efektif \\
& untuk semua pelajar. \\
& - Semua mitra yang bekerja dengan pelajar dan keluarganya memahami dan \\
& mendukung nasional tujuan kebijakan untuk mempromosikan inklusi dan \\
& kesetaraan dalam pendidikan. \\
& - Ada sistem untuk memantau kehadiran, partisipasi, dan pencapaian semua peserta \\
& didik dalam sistem pendidikan \\
\hline Kebijakan & Dokumen kebijakan pendidikan nasional yang penting sangat menekankan pada \\
& inklusi dan keadilan. \\
& - Staf senior di tingkat nasional, kabupaten, dan sekolah memberikan kepemimpinan \\
& dalam inklusi dan keadilan dalam pendidikan \\
& - Para pemimpin di semua tingkatan mengartikulasikan tujuan kebijakan yang \\
& konsisten untuk mengembangkan inklusi dan kesetaraan praktik pendidikan. \\
& - Para pemimpin di semua tingkatan menantang pendidikan yang tidak inklusif, \\
& diskriminatif dan tidak adil praktek. \\
\hline - Ada dukungan berkualitas tinggi untuk pelajar yang rentan. \\
- Semua layanan dan lembaga yang terlibat dengan peserta didik dan keluarganya \\
Struktur \\
\& Sistemerja sama dimengoordinasikan kebijakan dan praktik pendidikan yang inklusif \\
dan adil.
\end{tabular}




\begin{tabular}{ll}
\hline - & Sumber daya, baik manusia maupun keuangan, didistribusikan denga cara yang \\
& berpotensi menguntungkan pelajar yang rentan. \\
- & Ada peran yang jelas dari ketentuan khusus, seperti sekolah dan unit khusus, dalam \\
mempromosikan inklusi dan kesetaraan dalam pendidikan.
\end{tabular}

Sumber: UNESCO (2017)

\section{Simpulan}

Pembentukan sekolah inklusif akan membutuhkan lebih dari sekedar implementasi kebijakan baru. Guru yang inovatif adalah kunci keberhasilan penerapan sistem inklusif di sekolah, meskipun membutuhkan waktu, dukungan berkelanjutan, dan pelatihan. Oleh karena itu, dibutuhkan komitmen jangka panjang untuk menyelenggarakan pendidikan inklusif. Dalam artikel ini menyajikan analisis komparatif dari temuan tiga studi independen yang bertujuan untuk mengidentifikasi dan mendeskripsikan sikap dan pengalaman guru dalam melaksanakan pendidikan inklusif di salah satu sekolah jenjang pendidikan anak usia dini.

Identifikasi termasuk pada ketiga studi termasuk pengetahuan, keterampilan dan pelatihan untuk pelaksanaan pendidikan inklusif; cukup memadainya pendidikan dan dukungan guru; fasilitas dan sumber daya yang cukup memadai, dan potensi efek pendidikan inklusif pada peserta didik. Pelaksanaan pendidikan inklusif akan berhasil karena sekolah tersebut menerapkan sesuai peraturan. Pembelajaran Pendidikan Anak Usia Dini inklusif di sekolah tersebut telah dilakukan dengan baik sesuai peraturan pemerintah baik pusat dan pemerintah kota. Penyelenggaraannya humanisme, uniberalisme, pluralisme, demografi, dan menghormati hak azasi manusia. Sekolah juga sudah melaksanaan pengembangan pengelolaan PAUD menggunakan manajemen berbasis sekolah. Hambatan dan kendala yang dihadapi antara lain adalah bahwa pihak pemerintah hanya sekedar mengisyaratkan untuk menerima PAUD inklusi tanpa memberikan sarana dan prasarana yang baik. Belum ada kelas khusus untuk anak inklusi yang berbasis anak usia dini, masih bersatu dengan anak-anak normal dalam pembelajarannya. Sarana dan prasarana yang sudah sangat baik untuk anak usia dini inlkusif, sudah banyaknya alat permainan edukatif yang khusus untuk anak pendidikan anak usia dini. Fasilitas khusus untuk anak optimalisasi progam, sudah berjalan secara optimal, dan guru pembimbing khusus maupun guru kelas sudah cukup baik dalam mempersiapkan. Adapun sarannya perlu diterbitkan surat keputusan yang berkekuatan hukum agar semua pendidikan anak usia dini bersifat inklusif. Guru/Miss sebaiknya mempunyai waktu yang seimbang antara menghadapi anak yang biasa dan anak yang berkebutuhan khusus. Perlu ditingkatkan kembali kemampuan guru dalam menghadapi anak inklusif agar sesuai dan tepat sasaran.

\section{Daftar Rujukan}

Darma, I. P., \& Rusyidi, B. (2015). Pelaksanaan sekolah inklusi di Indonesia. Prosiding Penelitian dan Pengabdian kepada Masyarakat, 2(2). 
Ediyanto, E., Atika, I. N., Kawai, N., \& Prabowo, E. (2017). Inclusive education in Indonesia from the perspective of Widyaiswara in Centre for Development and empowerment of teachers and education personnel of kindergartens and special Education. IJDS: Indonesian Journal of Disability Studies, 4(2), 104-116.

Ediyanto, E., Mulyadi, A., Supriatna, A., \& Kawai, N. (2018). The Education And Training Program Guideline For Special Guidance Teacher Competence Development In Indonesian Inclusive School. IJDS: Indonesian Journal of Disability Studies, 5(2), 251-267.

Insiatun. (2016). Keterampilan Dalam Pembuatan Pot dari Stik Eskrim Pada Anak Tunagrahita Ringan Kelas XI di SLB Angkasa Lanud Sulaiman. Universitas Islam Nusantara.

Priyanti, M. M., Sudariyah, S., Mahmudah, L., \& Salimi, M. (2016, August). Upaya Pemberdayaan Anak Berkebutuhan Khusus melalui Pembelajaran Kewirausahaan di SLB Negeri Purworejo. In Prosiding Seminar Nasional Inovasi Pendidikan.

Purwani, A. (2014). Strategi Pembelajaran Pendidikan Agama Islam Di Sd Negeri 03 Brengkok Kecamatan Susukan Kabupaten Banjarnegara Tahun Pelajaran 2013/3014 (Doctoral Dissertation, Iain Purwokerto).

UNESCO (2017). A guide for ensuring inclusion and equity in education. Paris: UNESCO. Retrieved from: http://unesdoc.unesco.org/images/0024/002482/248254e.pdf

Windarsih, C. A., Jumiatin, D., Efrizal, E., Sumini, N., \& Utami, L. O. (2017). Implementasi Pendidikan Anak Usia Dini Inklusif Dikota Cimahi Jawa Barat. Jurnal Ilmiah P2M STKIP Siliwangi, 4(2), 7-11. 